\title{
Empowering Patients and Health Professionals in the Arab World: The King Abdullah bin Abdulaziz Arabic Health Encyclopedia on the Web
}

\author{
M. M. Altuwaijri \\ The College of Public Health and Health Informatics, King Saud bin Abdulaziz University for Health \\ Sciences (KSAU-HS), Riyadh, Saudi Arabia
}

\begin{abstract}
Summary
Objective: The purpose of this paper is to describe the needs and the process of establishing an online Arabic health encyclopedia to empower patients and health professionals with trustworthy information.

Methods: Astudy was conducted by King Saud bin Abdulaziz University for Health Sciences in collaboration with Health on the Net (HON) Foundation to review the quality of Arabic health information on the internet. A review of health portals in other languages was performed. Meetings were conducted to investigate areas of collaboration with different stakeholders including: WHO, HON, the U.S. National Library of Medicine, and the NHS.

Results: The results of the assessment of Arabic health sites showed that a very small percentage (almost 4\%) meets international standards. The study results call for immediate action to improve the trustworthiness of Arabic health information on the net. This will be achieved by establishing a reliable Arabic health encyclopedia and by encouraging health professional sfrom all Arab countries to contribute to its creation. It i i important for the 300 million Arabic citizens around the world to be able to access valuable health information on the internet.

Conclusions: More than 300 million Arab citizens around the world have missed the opportunity to use the internet to provide them with quality health information. Hence, to bridge this gap, a new project was launched to develop an online Arabic health encyclopedia.

Moreover, this study proposes an Arabic health information foundation be established to govern and accredit the Arabic health websites, and to work in collaboration with HON, to regulate and promote the qual ity of health information on the internet in Arab countries.
\end{abstract}

\section{Keywords}

Internet, health information seeking, personal health, consumer health, health encyclopedia

Yearb Med Inform 2011:125-30

\section{Background}

Work on this program began in 2008 in the college of Public Health and Health Informatics, King Saud bin Abdulaziz University (KSAU-HS), Riyadh Saudi Arabia. It is a newly founded university, established in early 2004, that specializes in health sciences. This university is known regionally for its efforts to promote the field of ehealth. The University offers a Master program in Health Informatics (HI) in order to provide advanced health informatics education and to prepare health informatics specialists who will be able to participate in research and in the advancement of the e-health field. To date, the program has produced more than 60 graduates.

\section{Introduction}

With the advancement of information and communication technology (ICT), there has been an evolution in the "information age" that is mirrored in the exponential growth in the number of web sites and online accessible databases, and in the expansion of services and publications available on the internet $[1,2]$. The worldwide-web has become an exceptional tool for people seeking health information. Health websites range from description of personal experiences with illnesses and patient' discussion groups to peer-re- viewed journal articles and clinical decision support tools [3].

While studies suggest that doctors are still regarded as the most trusted source of health information, there is a rapid increase in people relying on the internet for health information $[4,5]$. There are several reasons for this trend including the following:

- The internet offers convenient access to an unprecedented amount of health information.

- There is a new emphasis on people taking ownership of their health and well-being.

- There are recognized financial benefits to providing online health information.

- There are time-constrains in the consultation room and long average time to get an appointment with a doctor.

- More people are turning to the internet to get a health advice on important but sensitive matters.

- Some people want to be better informed and prepared to discuss their health issues before meeting their doctors [6].

As a result, health information has become one of the most frequently searched for topics on the web. The recent findings from the Pew Internet \& American Life Project shows that $61 \%$ of American adults looked online for health information in 2009, compared with only $25 \%$ of American adults who looked online for health information in 
2000 [7]. Moreover, the information retrieved online by individuals is often shared with others. Almost two-thirds of these individuals talk with friends or spouses about the health information they find online. The study also shows that online health information has a major impact on health care in the following ways [7]:

- $60 \%$ said the information found online affected a decision about how to treat an illness

- $56 \%$ said it changed their overall approach to maintaining their health

- $53 \%$ said it led them to ask a doctor new questions or to obtain a second opinion from another doctor.

- $49 \%$ said it changed the way they think about diet, exercise, or stress management.

- $38 \%$ said it affected a decision about whether to see a doctor or not.

- $38 \%$ said it changed the way they cope with a chronic condition or manage pain.

In the Health On the Net (HON) survey conducted in 2005 [8], the most important indicators of quality and usefulness for health websites are the availability of information, the ease of finding information, and the trustworthiness and the accuracy of the information. The majority of patient-respondents $(90 \%)$ said that healthcare providers should suggest trustworthy online sources for health information. Of the medical professionals surveyed, $77 \%$ agreed that patients seeking health information on the internet would improve the quality of patient consultation. However, $67 \%$ of health professionals reported that there would be a risk of patient self-treatment and $60.4 \%$ of them complained that seeking information on the internet would encourage patients to challenge the physician's medical authority.

Despite the availability of extensive amounts of information, it is difficult to differentiate its reliability. A crucial concern is that patients often directly apply the information they read on the web to their own lives, but there is an extreme variability in the quality of health information on the internet, which ranges from beneficial to harmful [9]. Therefore national governments and medical societies have also recognized their responsibility to help users identify "good quality" information sources y, through the development of a number of evaluation tools and criteria designed to direct consumers to good source of information [1].

The availability of quality Arabic health information online is not encouraging, because most Arabic health sites do not conform to international standards. As a result more than 300 million Arab citizens in the world are denied the opportunity to obtain reliable and credible health information in their native language. KSAU-HS, through its department of Health Informatics, has realized this deficiency and has been working with other national and international organizations to bridge this gap.

In this paper, the efforts of KSAUHS to establish an on-line Arabic health encyclopedia are presented.

The paper is organized as follows: An assessment of online Arabic health information follows this introduction, followed by a description of the King Abdullah bin Abdulaziz Arabic health encyclopedia. The paper then ends with the conclusion which includes some recommendations.

\section{HONcode}

HON, a not for profit organization, is one of the leading organizations in promoting the deployment of useful and reliable online health information. In 1996, HON introduced the first Code of Conduct (HONcode) for online medical and health information [8]. The use of HONcode is especially active in developed countries including those speaking English, French, Spanish, Italian, Portuguese and German. There are more than 7,000 certified medical web sites in 78 countries. The HONcode certificate indicates that health websites meet eight ethical principles which improve the reliability of the health information they offer. These principles are as follows:

1. Authority (give qualifications of authors)

2. Complementarity (information to support, not replace)

3. Confidentiality (respect the privacy of site users)

4. Attribution (cite the sources and dates of medical information)

5. Justifiability (justification of claims / balanced and objective claims)

6. Transparency (accessibility, provide valid contact details)

7. Financial disclosure (provide details of funding)

8. Advertising (distinguish advertising from editorial content)

\section{Assessment of Online Arabic Health Information}

Najeeb Al-Shorbaji indicated that internet connections and web presence at health care institutions in the Middle East are still suffering from the digital divide [10]. Eighteen out of twenty two Arab countries have established websites. These websites vary in quality; most of them are not built to function as e-health tools for health professionals and the public. Instead, they provide information related to the ministry's structure, activities, departments, etc. but do not provide healthcare services or health and medical advice [10].

The trustworthiness of Arabic health content had not yet been assessed, therefore KSAU-HS in collaboration with HON and Geneva University, have conducted a study in 2009 to accomplish the following tasks [11]:

1, Explore and describe Arabic health content on the internet.

2, Evaluate and assess Arabic health websites according to HONcode.

3, Understand the Arab health professionals' use of online health information. 


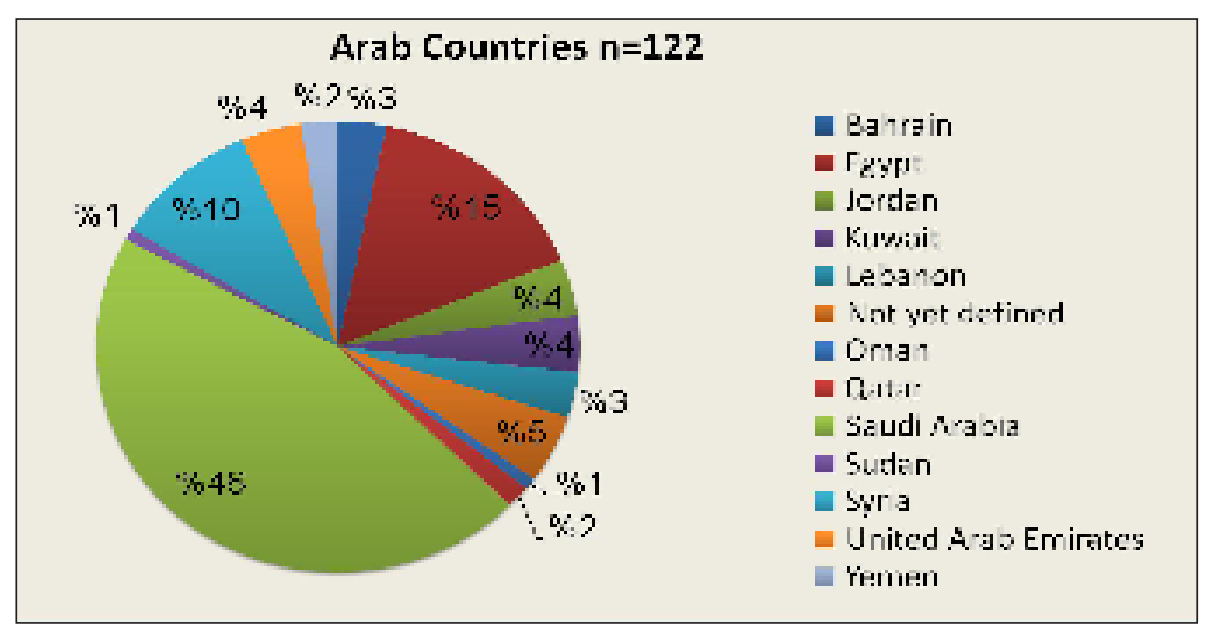

Fig. 1 Arabic Websites assessed grouped by country

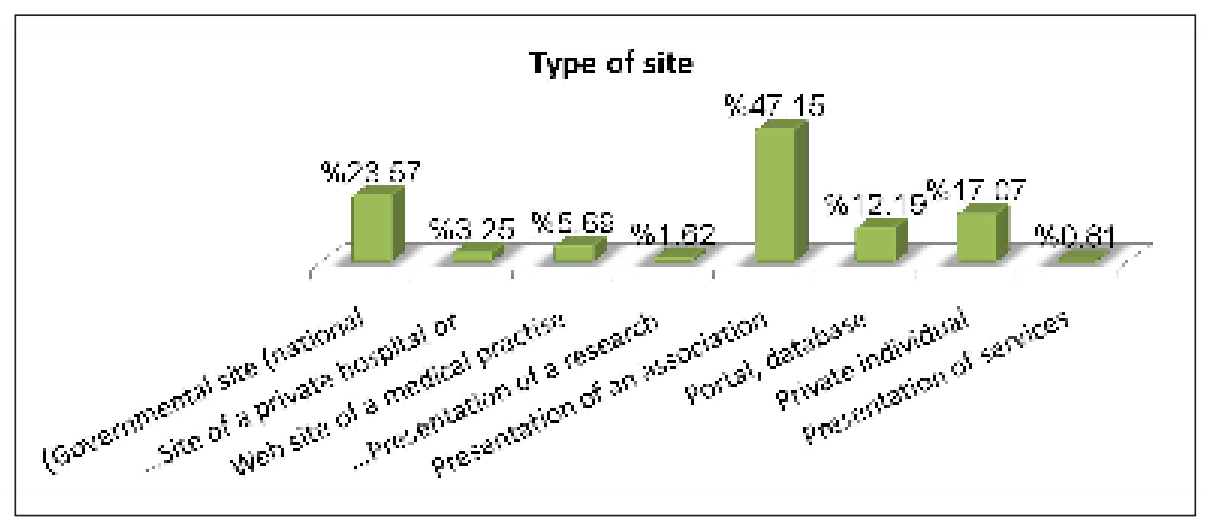

Fig. 2 Typology of the websites assessed

During the study, which was part of a graduation project for the Master's program in HI at KSAU_HS, an inventory of health websites in the Arab countries was conducted, which resulted in a list of 212 accessible websites. A sampling of 122 websites was randomly selected from the list and was evaluated according to the HONcode certification tool. Figure 1 shows the list of Arabic websites grouped by country. The majority of the sites were presented by associations (47.15\%), yet it was noticed that these associations were only established to support patients of certain diseases and their families. Only $12.19 \%$ of the sites represented a portal as shown in Figure 2. Evaluations were done on the HON platform based on the 8 principles listed above.
The result of the assessment showed that only 5 sites were compliant with all of the HONcode principles representing only $4.16 \%$ of the sample. The result of this assessment was also compared with similar studies conducted for Europe and Africa as shown in Table 1. Most of the Arabic sites had weaknesses in respecting the Transparency, Authoritativeness and Justifiability principles. The study also included a survey to identify the confidence of Arab health professionals in the Arabic health information available online. The study indicated that $79 \%$ of Arabic health professionals would not trust the quality of Arabic health information online.

The deficiency of credible Arabic health information on the web resulted in a call for immediate action to pro- mote the quality of Arabic health websites, in order to improve its trustworthiness. This resulted in some health portal developed in the Arab world including a website developed in the UAE by Mubadala that is bilingual and contains some health information [12]. It is however not HON accredited.

\section{The Arabic Health Encyclopedia on the Web}

\section{Purpose}

KSAU-HS and the Saudi Association for Health Informatics (SAHI) initiated the Arabic health encyclopedia project in May 2010. The main objective of the project is to establish a reliable Arabic health encyclopedia for the Arab community and to encourage health professionals from all of the Arabic countries to contribute to its creation. This encyclopedia will be targeted at the general population, professionals, and students.

The second objective of the project is to create a culture of reliable and credible Arabic health information on the web by promoting quality certifications. The encyclopedia will include links to Arabic websites that have been certified. This objective will be achieved through close collaboration with the HON organization.

The project due to its importance was presented to King Abdullah of Saudi Arabia and was approved officially and was announced during the Saudi Ehealth conference in Riyadh, Saudi Arabia in May 2010.

\section{Project Planning}

The project team has identified the promotion of this project internationally as the first and most important task. The project team identified the support of two organizations, WHO and HON, as a key factor for success. The first organization is the World Health Or- 
Table 1 Comparison of assessment between Middle East, Africa, and Europe

\begin{tabular}{l|l|l|l|}
\hline HONcode & Africa (2007) & Europe (2006) & Middle East (2009) \\
\hline Autoritative & $93 \%$ & $81.2 \%$ & $59.84 \%$ \\
Complementarity & $68.6 \%$ & $86 \%$ & $27.87 \%$ \\
Confidentiality & $4.8 \%$ & $75.3 \%$ & $31.97 \%$ \\
Reference & $94.3 \%$ & $91.9 \%$ & $58.20 \%$ \\
Date & $58.1 \%$ & $79.7 \%$ & $59.02 \%$ \\
Justifiability & $99 \%$ & $99.7 \%$ & $72.96 \%$ \\
Transparency & $96.2 \%$ & $99 \%$ & $82.79 \%$ \\
Financial disclosure & $77.2 \%$ & $77 \%$ & $36.89 \%$ \\
Advertising policy & $82.8 \%$ & $74.4 \%$ & $16.40 \%$ \\
\hline
\end{tabular}

ganization (WHO), which is responsible for providing leadership on global health matters, shaping the health research agenda, setting norms and standards, articulating evidence-based policy options, providing technical support to countries, and monitoring and assessing health trends. The Arabic language is one of WHO's six official languages established by a 1978 World Health Assembly resolution. WHO's role in this project is to review and approve the health content and to ensure the quality of the information offered.

The second key organization to support this project is HON which has developed a French health portal called „SantéRomande“ [13]. This project was mandated by the Geneva State in 2004. HON's role in this project is to provide the technical expertise needed to develop the encyclopedia.

A meeting between the project team and officials from WHO and HON took place at the WHO office in Geneva in July 2010 to discuss the main steps needed to create the Arabic health encyclopedia and to investigate the areas of possible collaboration between these three organizations. The group agreed to the following:

1. To develop an initial mock-up to be used to illustrate the services provided by the encyclopedia.

2 . To establish a project team responsible for developing and maintaining the encyclopedia. The team should include technical expertise as well as medical doctors with linguistics expertise.

3. To organize a 2-day symposium in Riyadh, Saudi Arabia, at the end of March 2011 to review the progress of the project. The symposium will be attended by WHO, HON, and other key stakeholders.

4. To finalize the legal agreements between the parties involved in this project.

5. To establish a governing board for the encyclopedia in order to govern the strategies and to monitor the progress.

6. To establish an editorial board to review and approve the content.

Furthermore, the encyclopedia project manager was invited to the HON board meeting in Zurich in October 2010 to present the project to the board members in order to get their support and to solicit new ideas for the encyclopedia. During this event, there was a meeting with the Director of the U.S. National Library of Medicine (NLM) to seek the support of the NLM and to benefit from the NLM's "MedlinePlus" website, which offers reliable, up-to-date health information in English and Spanish [14]. The meeting resulted in the generous support of the NLM for this project and the authorization to use health information owned by the NLM in the Arabic encyclopedia.
The project was also presented to distinguished Arab doctors who are members of the Arabization of Health Sciences Network (AHSN) at their $8^{\text {th }}$ meeting organized by WHO in Cairo, Egypt in December 2010. The recommendations from the meeting included enlisting the support of the network for this initiative and calling upon medical doctors and public health specialists to contribute.

Furthermore, the project team had a conference call with a senior NHS official in January 2011 which resulted in a syndication agreement for the NHS health portal called „Choices“ [15].

\section{Project Phases}

Because of the importance and the size of this project, the Arabic encyclopedia will be established in multiple phases; in order for it to achieve its ultimate goal of providing quality Arabic health information on the internet. The project will be carried in 4 phases.

\section{Phase 1: Mock-up Phase}

The goal of this phase is to explore issues related to graphic designs, ergonomics, functionalities and content production workflows. Moreover, all services are presented on a mock-up website in order to stimulate and focus the discussions between all project teams. This phase was outsourced to the HON foundation and was accomplished in December 2010. The main deliverables of the project include the following:

- A graphic and ergonomics concept for the Encyclopedia's website.

- An illustrated set of potential content and services

- Identification and evaluation of potential content sources.

- An analysis of the workflow for coordinated content management including authoring, validation, translation, editing and quality assurance.

Elements of the site include general services, localized services and personalized 
services as shown in Figure 3. The general services include the following:

- An encyclopedia of health topics including articles on complementary and preventive medicine.

- A medical dictionary.

- A drug database

- Easily accessible information access through key criteria (age, gender, etc.)

- Health related news through syndication.

- A newsletter

- Health tutorials

- Video streaming and podcast.

- Improved accessibility tools.

The localized services include a directory of health associations, hospitals, clinics, health services and health professionals in the Arab world.

The personalized services include: subscription to specific information services, mobile phone access, social networking (Twitter, Facebook, etc.) and personal health tools.
With regard to the source of the content, the project team has decided to rely on health information produced by WHO, NHS, and NLM, in addition to health information produced by Arab health professionals. Agreements were signed between the encyclopedia and these organizations for content syndication. Figure 4 shows a simplified version of the workflow used in this project for content production.

Phase 2: Establish Core Database and publish first version of the encyclopedia (6 Months).

In this phase, the encyclopedia will cover limited number of health topics (200 health topics). This phase will cover most of the services, including video streaming and multimedia. The content will include a directory of diseases, a directory of drugs, and articles on complementary and preventive medicine. In this phase a directory of most of the associations, hospitals, clinics, and health pro-

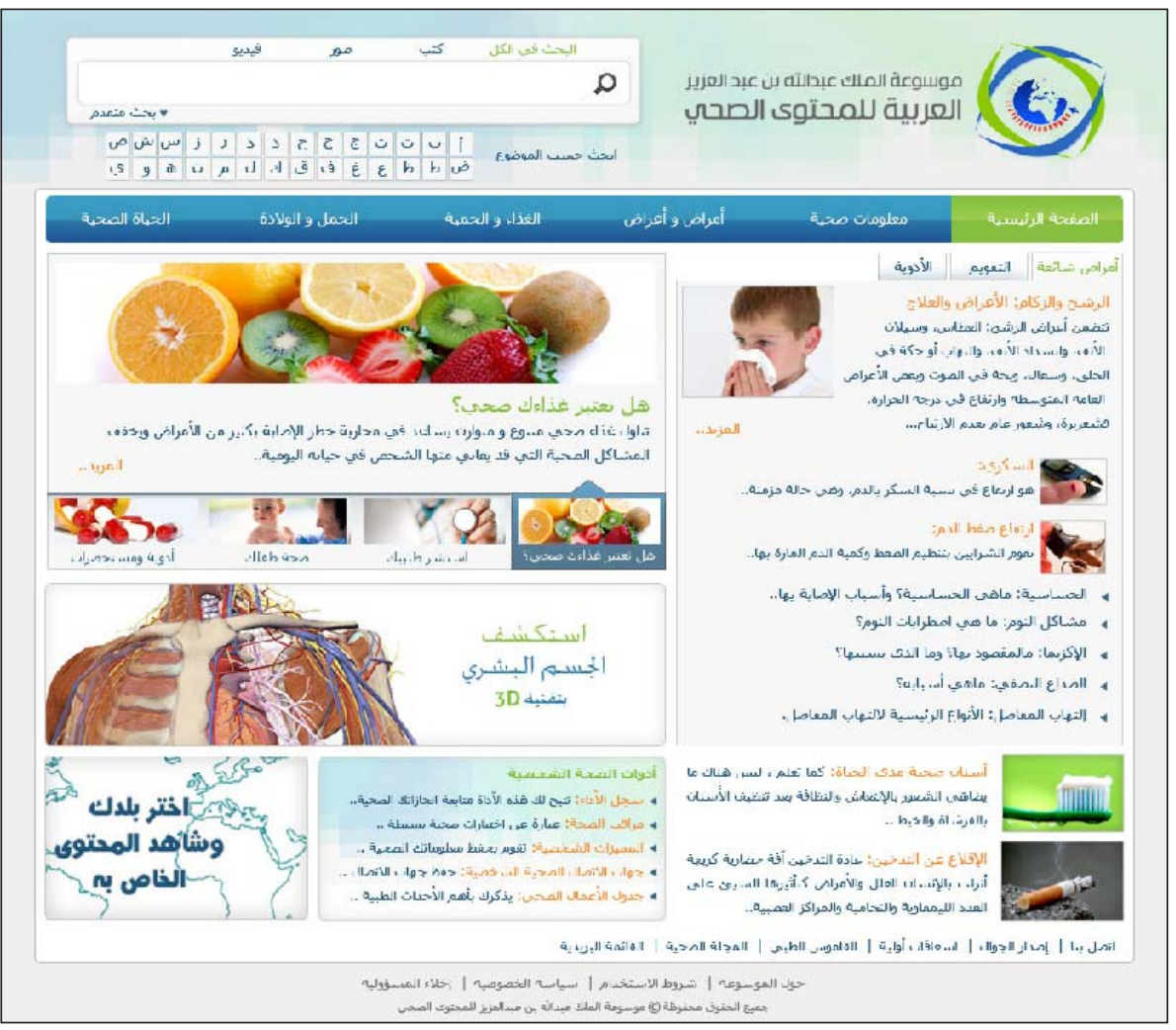

Fig. 3 The design of the Encyclopedia homepage showing the services offered in the first phase fessionals in the Arab world will be created. The first version of the encyclopedia will be launched online upon successful execution of this phase. This is expected to be accomplished by the end of July 2011.

Phase 3: Enhancement of Services. As the number of visitors and the involvement of health professionals increases, more health content will be added. This phase is a continuous process and will start immediately after Phase 2.

Phase 4: Promotion of Scientific Research. Scientific research will be promoted by encouraging research centers to present their findings to health professionals. The encyclopedia will include: statistics (epidemiology), scientific articles, case studies, clinical trials and on-going research.

\section{Project Stakeholders}

1. KSAU-HS and SAHI which will provide financial and knowledge support and overall project management.

2. WHO which will provide knowledge support, editing, certification, and promotion of the project across all Arabic-speaking countries.

3. The HON Foundation which will provide the technical expertise and knowledge in the area of health related sites.

4. The U.K. National Health Services and the U.S. National Library of Medicine, which will support the encyclopedia with content.

5. Health professionals from all over the Arab world who will contribute with knowledge.

\section{Conclusions}

This article presented the efforts of KSAU-HS for promoting trustworthy health information on the web. The King Abdullah bin Abdulaziz encyclopedia for Arabic health content is a project that is intended to serve more than 300 million 


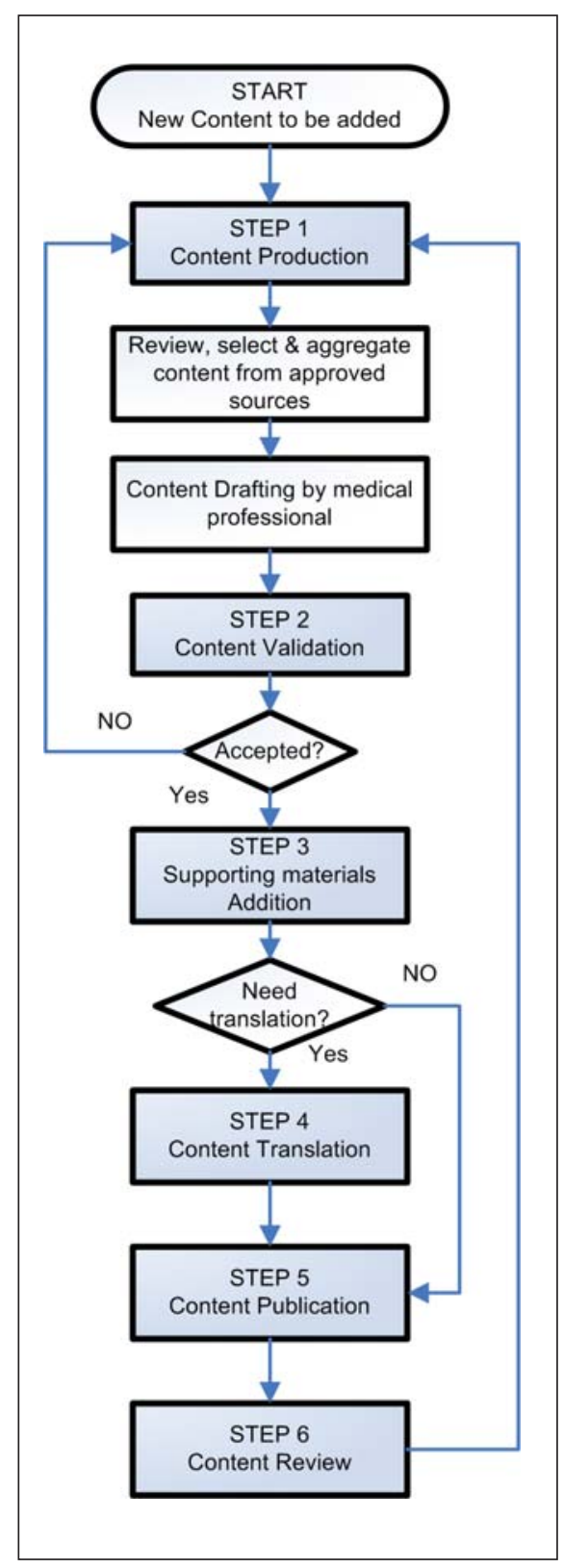

Fig. 4 Simplified workflow for adding new content
Arab citizens around the world. Because this project is under development, we call upon the readers to send any suggestions or recommendation that might enhance the value of the encyclopedia. Finally, the following recommendations are worth considering:

- Health professionals in Arab countries must collaborate in order to improve the quality of health information on the web by promoting the awareness of the importance of quality health websites.

- Encourage the initiation of reliable health websites, by creating awards that are given to those reliable and extraordinary health websites that have made efforts to improve their quality in a competitive way.

- Encourage owners of health websites to seek certification.

- Include health informatics courses in the medical study field, with an emphasis on how to judge the reliability of health information on the net, because we are in the information era and the internet is a rich source of information.

\section{Acknowledgment}

The author would like to acknowledge the efforts of Prof. A. Geissbuhler, C. Boyer from HON, Dr. N. Alshorbaji, Dr. K. Sara from WHO, Dr. D. Lindberg from NLM, B. Gann from NHS, and all the KSAU_HS team for their support.

\section{References}

1. Suominen O, Hyvonen E, Viljanen K, Hukka E. HealthFinland - A national semantic publishing network and portal for health information. J Web Semantic 2009; 7: 287-97.
2. D'Auria J. In Search of Quality Health Information J Pediatr Health Care 2010;24:137-40.

3. Lemire M, Pare G, Sicotte C, Harvey C. Determinants of Internet use as a preferred source of information on personal health. Int J Med Inform 2008;77:723-34

4. Sillence E, Briggs P, Harris P, Fishwick L. Health Websites that people can trust- the case of hypertension. Interacting with Computers 2007; 19:32-42.

5. Sillence E, Briggs P, Harris P, Fishwick L. How do patients evaluate and make use of online health information? Social Science \& Medicine 2007; 64: $1853-62$

6. Buhi E, Daley E, Oberne A, Smith S, Schneider T, Fuhrmann H. Quality and Accuracy of Sexual Health Information Web Sites Visited by Young People. J Adolesc Health 2010;47:206-8.

7. Fox S, Jones S. The Social life of health information. Pew Internet \& American Project 2009. Retrieved from http://www.pewinternet.org.

8. Health On the Net Foundation. Analysis of the $9^{\text {th }}$ HON survey of health and medical Internet users 2005. Retrieved from www.hon.ch.

9. Wald H, Dube C, Anthony D. Untangling the Web-The impact of Internet use on health care an the physician- patient relationship. Patient Educ Couns 2007:68:218-24.

10. Al-Shorbaji N. e-health in the Eastern Mediterranean Region: a decade of challenges and achievements. East Mediterr Health J (14):157-73.

11. AlHuziah M, AlKahtany M, AlAmmari R, AlFaiz $\mathrm{R}$, Boyer C, Altuwaijri M, et al. Assessment of Online Health Information for Arabic Sites. MS Project Report.KSAU_HS 2009.

12. Minhaal health portal. http://www.minhaal.ae/ portal $/$ portal $/ \mathrm{mhp} /$

13. SanteRomane Health Portal. http:// www.santeromande.ch

14. NLM MedlinePlus. http://www. nlm. nih.gov / medlineplus/.

15. NHS Choices. http://www.nhs. uk/Pages HomePage.aspx.

Correspondence to:

Maijd Altuwaiji, Ph.D.

College of Public Health \& Health Informatics

P.O. Box 22490, Riyadh 11426

Saudi Arabio

Tel: +96612520088 xtn.

E-mail: majid @ngha.med.sa 